\title{
Experimental Studies on the Effect of Ceramic Fine Aggregate on the Partial Replacement of Sand Is an One of Ingredients in Concrete
}

\author{
A.R.Pradeep ${ }^{1}$, M.I.Basava lingana Gowda ${ }^{2}$ \\ ${ }^{\text {I}}$ (Asst.Profesor,Department of Civil Engineering , Sri Siddhartha Institute of Technology Engineering College \\ Tumakuru, Karnarnaaka ,India) \\ ${ }_{2}^{2}$ (Asst.Profesor Department of Civil Engineering, Rao Bahadur Y. Mahabaleswarappa Engineering College, \\ Ballari, Karnarnaaka ,India)
}

\begin{abstract}
Scarcity of the construction materials using the natural resources like sand aggregate and stone aggregate. The partial replacement of aggregates is required for the future generation of concrete structures for the environment sustainability. The depletion of the natural resource get exhausted. We have thick over the alternate replacement of the materials. The replacement of materials calculating concrete strength in the various parameter like compressive strength of cube, split tensile strength of cylinder and flexure strength of prism. The result is interpolated in the replacement of the ceramic fine aggregate with the convention concrete. The comparisons of the parameter are compression strength of cube, split tensile strength of cylinder and flexure strength of prism.
\end{abstract}

Keywords: Cement, Coarsse aggeregte,Compression Stength,FlexureStrenght,Fine aggregate, Split tensile strength,Ceramic fine aggregate, Water.

\section{Introduction}

The ceramic waste from ceramic and construction industries is a major contribute to construction and demolition waste, representing a serious environmental, technical and economical problem of society nowadays. The major sources of ceramic waste are ceramic industry, building construction and building demolition. It has been estimated that about $30 \%$ of the daily production in the ceramic industry goes to waste. This waste is not recycled in any form at present. However, the ceramic waste is durable, hard and highly resistant to biological, chemical and physical degradation forces. As the ceramic waste is piling up every day, there is pressure on the ceramic industries to find a solution for its disposal (RM Sentharamai, 2005). Properties of fresh and hardened concrete using ceramic waste as coarse aggregate and bottom ash as fine aggregate is compared with the properties of conventional concrete (S Karthikkrishnan, 2006). Rock flour can be effectively used as fine aggregate in place of conventional river sand, in concrete. Ceramic scrap can be partially used to replace conventional coarse aggregates (10\% and 20\%), without affecting its structural significance (MV Reddy, 2007).

Homogeneous ceramic tiles waste can be used as a replacement to natural crushed stones, as their properties are similar as natural coarse aggregates (Mashitah MD, 2008). Recycled concrete obtained through partial substitution of natural coarse aggregate is suitable for structural purposes (C Medina Martinez, Nov.2009). Investigation has been made on physical and mechanical properties of concrete mixed under laboratory conditions. Different proportions of coarse aggregate materials were substituted by porcelain from ceramic installations. Concrete made with porcelain debris as a substitute for part of the coarse aggregates is technically viable (I Guerra, 2009). Concrete with ceramic waste powder has a minor strength loss but possess increased durability performance because of its pozzolanic properties. As for the replacement of traditional coarse aggregates by ceramic coarse aggregates, the results are promising but they underperform slightly in water absorption meaning that the replacement of traditional sand by ceramic sand is a better option (F PachecoTorgal, 2010).

In the present study, the tests have been carried out for different trial mixes by gradual substitution of ceramic fine aggregate. 


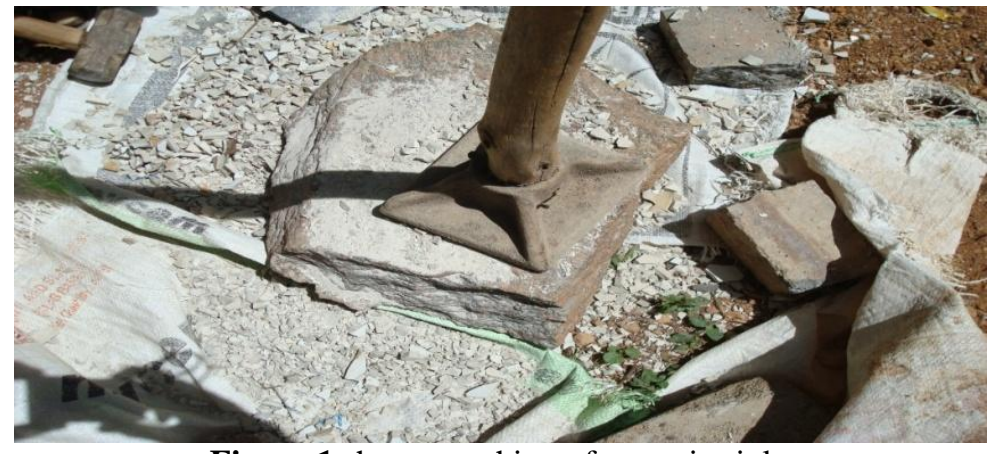

Figure 1 shows crushing of ceramic sinks.

\subsection{Materials}

\section{Experimental Programme}

\subsubsection{Cement}

PPC grade less cement is used for the laboratory investigations. The cement for the whole work was procured in a single consignment and properly stored. The properties of cement used in the investigation are presented in Table 2.1.

Table 2.1: Properties of Cement

\begin{tabular}{|c|c|c|}
\hline Property & & Value \\
\hline Specific Gravity & & 3.15 \\
\hline \multicolumn{2}{|c|}{ Standard Consistency (\%) } & 30.5 \\
\hline Initial setting time & (min) & $50 \mathrm{~min}$ \\
\hline Final setting time & $(\min )$ & $580 \mathrm{~min}$ \\
\hline \multicolumn{2}{|c|}{ Compressive strength } & \\
\hline @ 3days in $\mathrm{MPa}$ & & 16.5 \\
\hline @7days in $\mathrm{MPa}$ & & 23.5 \\
\hline
\end{tabular}

\subsubsection{Fine aggregate}

\subsubsection{A. Sand}

River sand was used as fine aggregate. The properties of sand used in the investigation are presented in Table 2.2 .

Table 2.2: Properties of fine aggregate

\begin{tabular}{|l|l|}
\hline Property & Value \\
\hline Specific Gravity & 2.62 \\
\hline Water Absorption & $1.35 \%$ \\
\hline Fineness Modulus & 3.2 \\
\hline Bulk Density $\left(\mathrm{g} / \mathrm{cm}^{3}\right)$ & 1.52 \\
\hline Sieve Analysis & Well Graded \\
\hline
\end{tabular}

\subsubsection{B. Ceramic waste}

Ceramic wastes of different shapes and sizes can be procured from the ceramic industry and the shapes should be modified using manual operations. In this study, ceramic wastes were collected from sink, wash basin and urinals. These ceramic wastes were broken into small pieces and then crushed in a jaw crusher to get 4.75 $\mathrm{mm}$ down size fine aggregate. The properties of fine aggregate used in the study are presented in Table 2.3.

\section{Table 2.3: Properties of ceramic fine aggregate}

The particle size distribution of Ceramic fine aggregates and sand is shown in Figure 2.1. It is observed that, both ceramic fine aggregates and sand are confirming to Zone II.

Figure 2.1: Particle Size distribution

\begin{tabular}{|l|l|l|}
\hline Property & & Value \\
\hline Specific Gravity & & 1.89 \\
\hline Water Absorption & & $6.56 \%$ \\
\hline Bulk Density $\left(\mathrm{g} / \mathrm{cm}^{3}\right)$ & & 1.26 \\
\hline Impact Test & & $23.69 \%$ \\
\hline
\end{tabular}

The particle size distribution of Ceramic fine aggregates and sand is shown in Figure 2.1. It is observed that, both ceramic fine aggregates and sand are confirming to Zone II. 
Figure 2.1: Particle Size distribution

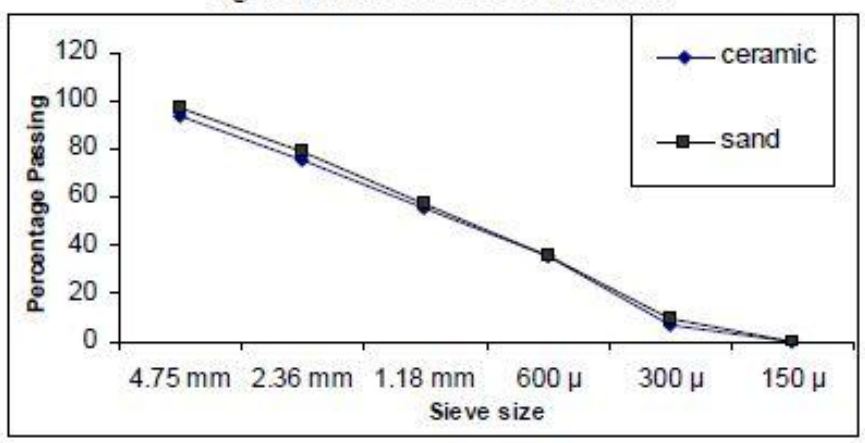

\subsection{Preparation of Specimens}

The quantities of the constituents of the concrete were obtained from the Indian Standard Mix Design Method (IS 10262:2007). The concrete was prepared in the laboratory using mixer. The cement, fine aggregate and coarse aggregate were fixed in dry state to obtain uniform colour and calculated amount of water, obtained from workability test, was added and the whole concrete was mixed for five minutes in wet state. Meanwhile the moulds were screwed tightly to avoid leakage. Oil was applied on inner surface of moulds in three layers by Poking with a tamping rod. The cast specimens were removed from moulds after 24 hours and the specimens were immersed in a clean water tank. After curing of specimens for a period of 28 days, the specimens were removed from the water tank and allowed to dry under shade.
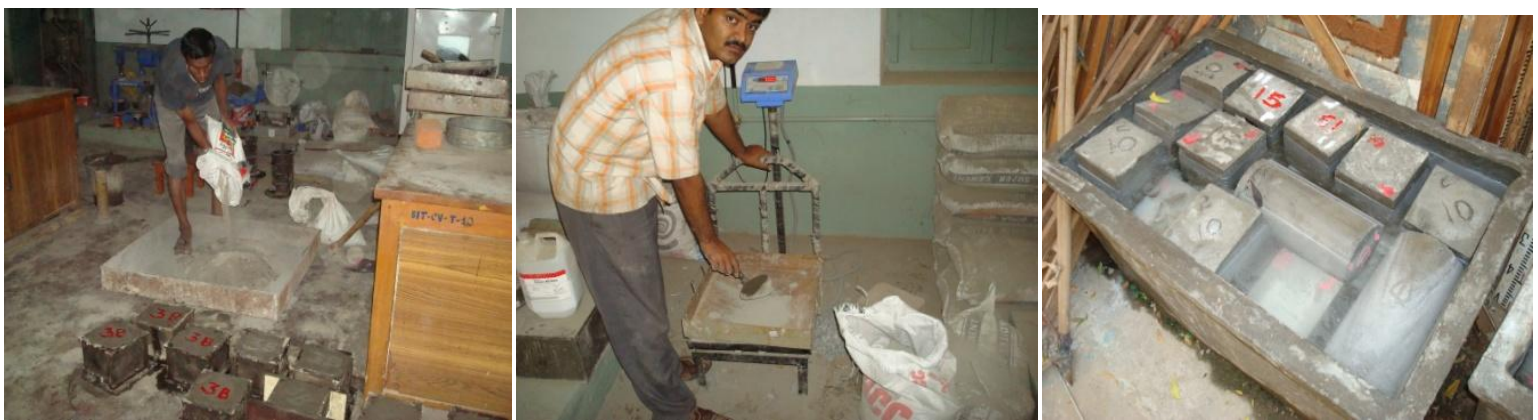

Figure 2.2 Shows Mixing of materials, weigthing of materials and curing of concrete.

\subsection{Tests}

Three cubes of $150 \mathrm{~mm}$ x $150 \mathrm{~mm}$ x $150 \mathrm{~mm}$ size were tested to determine compressive strength for 28 days. Three cylinders of $150 \mathrm{~mm}$ diameter x $300 \mathrm{~mm}$ height size were tested for split tensile strength. Three prisms of $100 \mathrm{~mm} \times 100 \mathrm{~mm} \times 450 \mathrm{~mm}$ size were tested in flexure to determine the flexural strength.

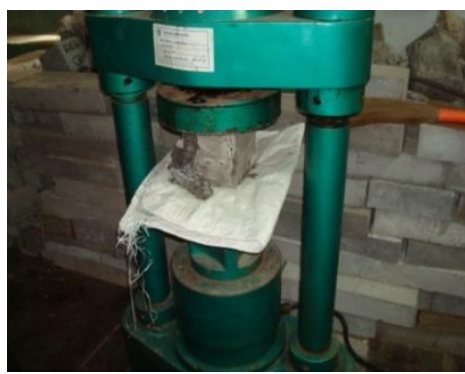

Figure 2.2 Shows testing of concrete

\subsection{Mix proportions}

The grade of concrete adopted for investigation was $\mathbf{M}_{35}$. In the present work, fine aggregate is replaced with ceramic fine aggregate. The mix proportion of conventional concrete (with $0 \%$ ceramic fine aggregate), $10 \%$ and $20 \%$ replacement of natural fine aggregate by ceramic fine aggregate is done along with varying cement content and coarse aggregates combination is indicated in Table 2.4 to Table 2.6. 


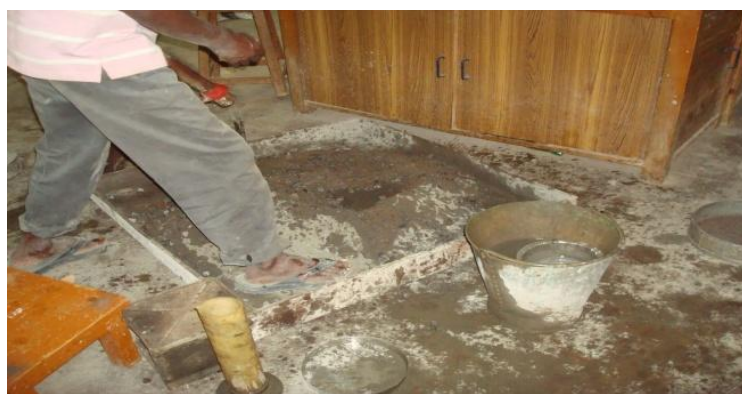

Figure 2.3 Shows the mixing of concrete

Table 2.4: Mix proportion for conventional concrete

\begin{tabular}{|l|l|l|l|}
\hline Mix & w/c & Cement & Proportions \\
\hline designation & (by weight) & $\mathbf{k g} / \mathbf{m}^{\mathbf{3}}$ & (by volume) \\
\hline & & & C:FA:CA10:CA20* \\
\hline M1 & 0.389 & 420 & $1: 1.76: 1.01: 1.63$ \\
\hline M2 & 0.392 & 400 & $1: 1.88: 1.08: 1.74$ \\
\hline M3 & 0.375 & 380 & $1: 2.04: 1.17: 1.89$ \\
\hline
\end{tabular}

Table 2.5: Mix proportion with $10 \%$ replacement of natural fine aggregate by ceramic fine aggregate

\begin{tabular}{|l|l|l|l|}
\hline \multicolumn{1}{|c|}{ Mix } & w/c & Cement & Proportions \\
\hline designation & (by weight) & $\mathbf{k g} / \mathbf{m}^{\mathbf{3}}$ & (by volume) \\
\hline & & & C:FA:CA10:CA20:CFA*** \\
\hline M4 & 0.410 & 420 & $1: 1.28: 0.98: 1.58: 0.428$ \\
\hline M5 & 0.414 & 400 & $1: 1.37: 1.05: 1.695: 0.458$ \\
\hline M6 & 0.396 & 380 & $1: 1.49: 1.14: 1.838: 0.496$ \\
\hline
\end{tabular}

Table 2.6: Mix proportion with $20 \%$ replacement of natural fine aggregate by ceramic fine aggregate

\begin{tabular}{|l|l|l|l|}
\hline Mix & w/c & Cement & Proportions \\
\hline designation & (by weight) & $\mathbf{k g}^{\mathbf{3}} \mathbf{m}^{\mathbf{3}}$ & (by volume) \\
\hline & & & C:FA:CA10:CA20:CFA** \\
\hline \hline M7 & 0.430 & 420 & $1: 0.833: 0.96: 1.54: 0.833$ \\
\hline M8 & 0.433 & 400 & $1: 0.875: 1.00: 1.62: 0.875$ \\
\hline M9 & 0.423 & 380 & $1: 0.976: 1.12: 1.79: 0.976$ \\
\hline
\end{tabular}

Cement : Sand: Coarse aggregate of $20 \mathrm{~mm}$ :Coarse aggregate $10 \mathrm{~mm}$ :Ceramic fine aggregate

\section{Experimental Results}

In the present investigation, compressive, split tensile and flexural strength of the concrete specimens were tested. Mix design is done as per IS: 10262-2007 [8]. As per the Mix design, the cement content works out to be $420 \mathrm{~kg} / \mathrm{m}^{3}$. In our study, the cement content is also varied along with the ceramic fine aggregates. The natural fine aggregate in concrete is replaced by ceramic fine aggregate up to $20 \%$. The compressive strength of concrete increases slightly with $10 \%$ replacement of ceramic coarse aggregate in concrete, which is observed in MV Reddy et.al (2007) is shown in Figure 3.1 to 3.3.

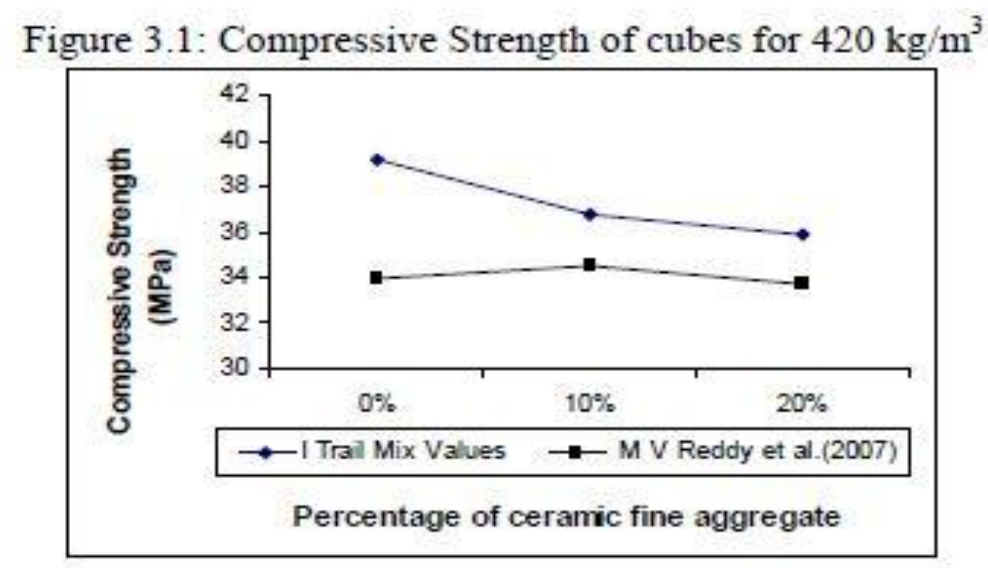


Figure 3.2: Compressive Strength of cubes for $400 \mathrm{~kg} / \mathrm{m}^{3}$

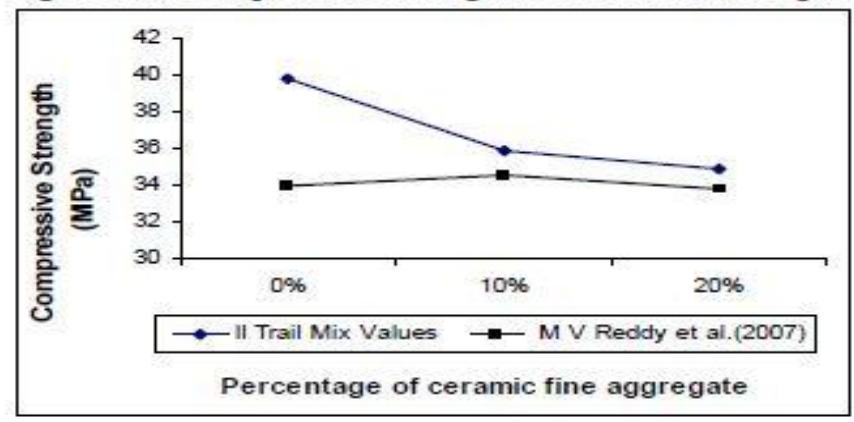

Figure 3.3: Compressive Strength of cubes for $380 \mathrm{~kg} / \mathrm{m}^{3}$

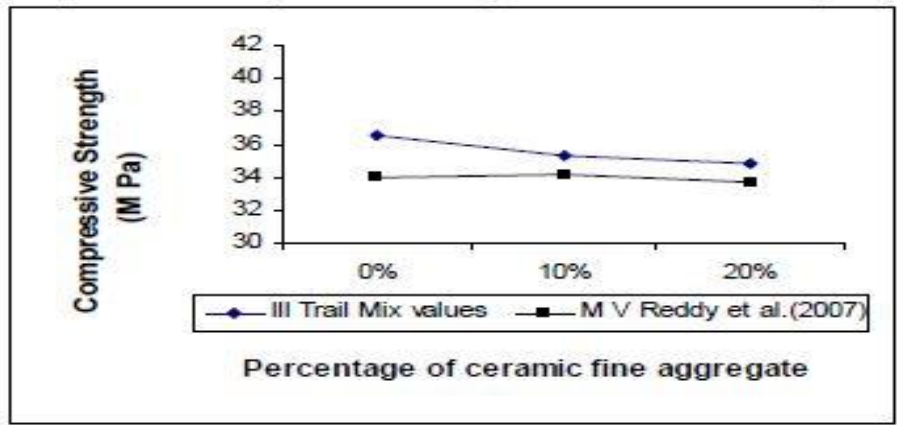

In our investigation, it is found that the compressive strength of concrete decreases slightly with increase in percentage of ceramic fine aggregates and also there is no much variation of strength with variation of cement content.

The split tensile strength of cylinders remains same with $10 \%$ and $20 \%$ replacement of ceramic coarse aggregate in concrete, which is observed in MV Reddy et.al (2007) is shown in Figure 3.4 to 3.6.

Figure 3.4: Split tensile strength of cylinders for $420 \mathrm{~kg} / \mathrm{m}^{3}$

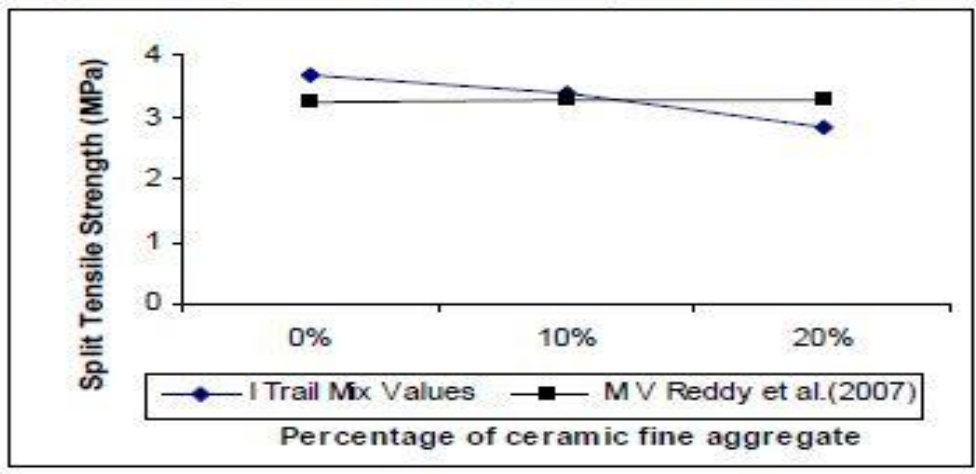

Figure 3.5: Split tensile strength of cylinders for $400 \mathrm{~kg} / \mathrm{m}^{3}$

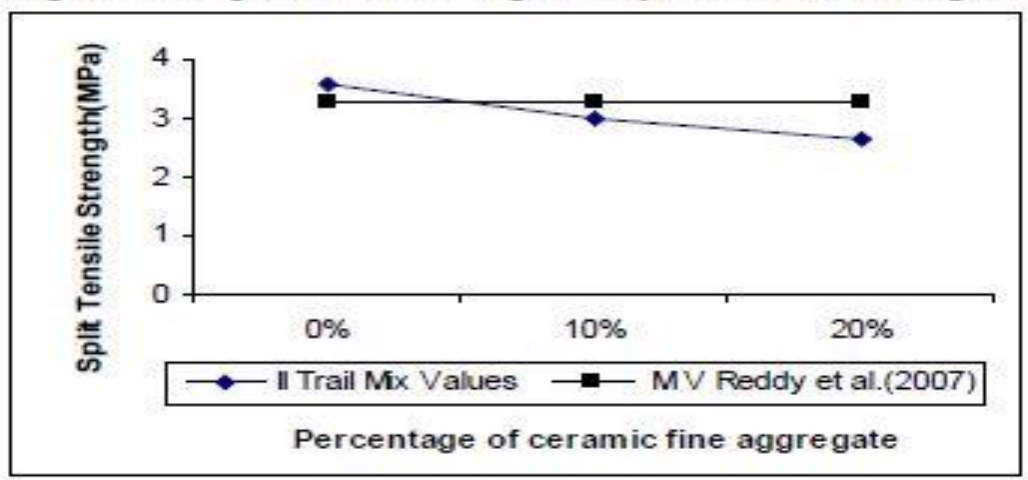


Figure 3.6: Split tensile strength of cylinders for $380 \mathrm{~kg} / \mathrm{m}^{3}$

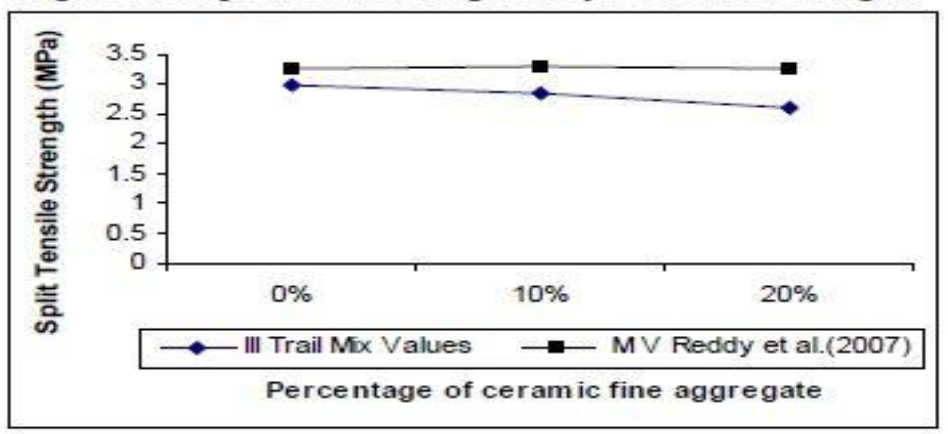

In our investigation, it is found that the split tensile strength of cylinders decreases slightly with increase in percentage of ceramic fine aggregates and also there is no much variation of strength with variation of cement content from $420 \mathrm{~kg} / \mathrm{m}^{3}$ to $380 \mathrm{~kg} / \mathrm{m}^{3}$.

The flexural strength of prisms remains, the same with increase in percentage of ceramic coarse aggregate is shown in MV Reddy et al (2007). In our investigation, it is found that flexural strength of concrete decreases slightly with increase in ceramic fine aggregate is shown in Figure 3.7 to 3.9.

Figure 3.7 Flexural strength of concrete for $420 \mathrm{~kg} / \mathrm{m}^{3}$

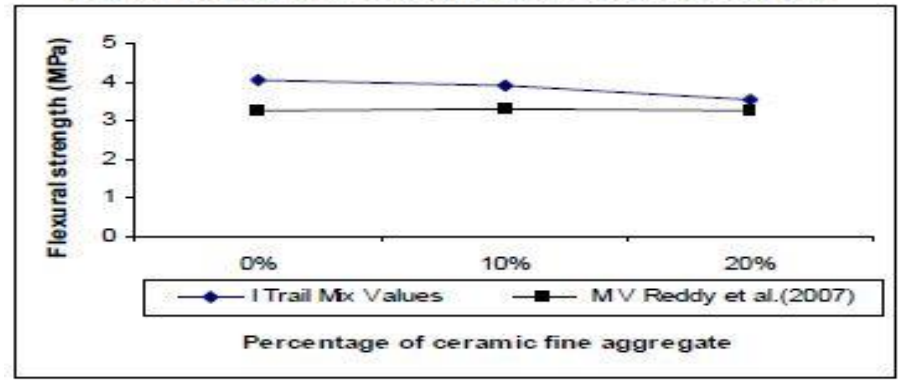

Figure 3.8 Flexural strength of concrete for $400 \mathrm{~kg} / \mathrm{m}^{3}$

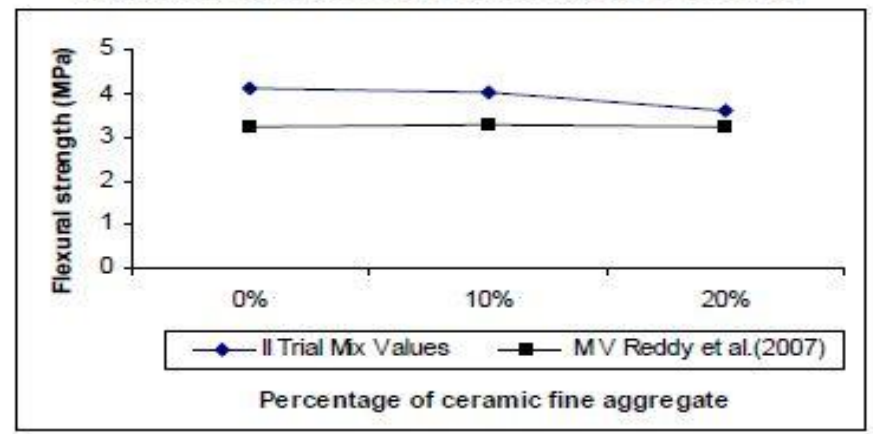

Figure 3.9 Flexural strength of concrete for $380 \mathrm{~kg} / \mathrm{m}^{3}$

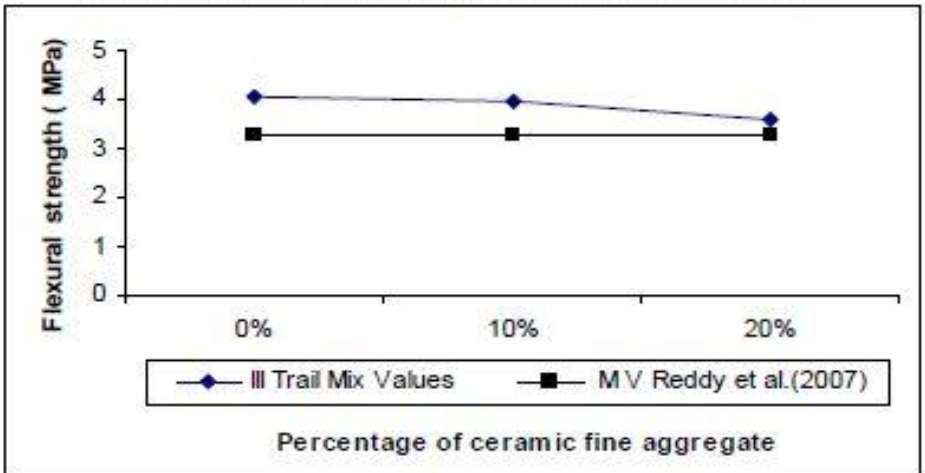




\section{Conclusions}

- The compressive strength of concrete slightly decreases with increase in percentage of ceramic fine aggregate in concrete but there is no much variation in compressive strength of concrete with the variation of cement content.

- The split tensile strength of concrete slightly decreases with increase in percentage of ceramic fine aggregate in concrete but there is no much variation in split tensile strength of concrete with the variation of cement content.

- The flexural strength of concrete slightly decreases with increase in percentage of ceramic fine aggregate but there is no much variation in split tensile strength of concrete with the variation of cement content.

\section{References}

[1]. R.M. Sentharamai, P Devadas Manoharam, "Concrete with ceramic waste aggregate," Cement \& Concrete Composites, 27, pp.910-913, 2005.

[2]. Mashitah M.D, Kin CC, Badorui AH, "Recycling of homogenous ceramic tiles for the production of concrete block", International Symposium on Environmental Management: Hazardous-Environmental Management Toward Sustainability, pp 25-28, 2008.

[3]. C. Medina Martinez, MI Guerra Romero, JM Moran del Pozo and A Juan Valdes, "Use of ceramic wastes in structurals concretes," $1^{\text {st }}$

[4]. Spanish national conference on advances in materials recycling and Eco-energy Maoria, 12-13, pp 137-139, Nov.2009.

[5]. F Pacheco-Torgal, S Jalali, "Reusing ceramic wastes in concrete," Construction and Building Materials, 24, pp 832-838, 2010.

[6]. I Guerra, I Vivar, B Llamas, A Juan, J Moran, "Eco-efficient concretes: The effects of using recycled ceramic material from sanitary installations on the mechanical properties of concrete," Waste Management, 29, pp 643-646, 2009.

[7]. S. Karthikkrishnan, Dr. R.M. Senthamarai, "Strength characteristics of concrete with ceracrete and bottom ash," National conference on recent developments in concrete technology, Government college of Technology, Coimbatore- 641013, 2006.

[8]. M.V. Reddy, C.N.V.S. Reddy, "An experimental study on use of Rock flour and insulator ceramic scrap in concrete," Journal of the Institution of Engineers, India, 88, pp 47-50, 2007.

[9]. IS: 10262-2007, "Recommended guidelines for concrete mix design," Bureau of Indian Standards, New Delhi. 